\title{
Towards an easier pleurodesis: Ultrasound-guided iodopovidone sclerotherapy in cirrhotic patients with hepatic hydrothorax
}

\author{
Ahmed M. Abdelhafeez ${ }^{1}$, Mohammed W. Zakaria ${ }^{1}$, Waleed F. Fathalah ${ }^{2 \#}$, Dalia Omran ${ }^{2}$ \\ ${ }^{1}$ Chest Department, Faculty of Medicine, Cairo University, Cairo, Egypt \\ ${ }^{2}$ Endemic Medicine and Hepatology Department, Faculty of Medicine, Cairo University, Cairo, Egypt \\ Email: ${ }^{*}$ walfou2000@gmail.com \\ Received 29 April 2013; revised 30 May 2013; accepted 10 June 2013 \\ Copyright (C) 2013 Ahmed M. Abdelhafeez et al. This is an open access article distributed under the Creative Commons Attribution \\ License, which permits unrestricted use, distribution, and reproduction in any medium, provided the original work is properly cited.
}

\section{ABSTRACT}

Background and Aim: Hepatic hydrothorax is one of the complications encountered in end stage liver disease. Pleural drainage carries the risk of massive protein and electrolyte depletion as well as the risk of bleeding and hepatic encephalopathy. Pleurodesis following pleural aspiration decreases the chance of pleural effusion recurrence, and has been a widely used long-standing method of controlling recurrent pleural effusions. The aim of this study is to evaluate the effect of pleurodesis using ultrasound-guided iodopovidone sclerotherapy in hepatic hydrothorax. Patients and Methods: This prospective study included 56 patients with clinical, laboratory and radiological evidence of liver cirrhosis and symptomatic right sided hepatic hydrothorax. All patients were subjected to repeated thoracentesis. Ten $\mathrm{ml}$ of lidocaine $2 \%$ were injected in the pleural space followed by 20 $\mathrm{ml}$ of iodopovidone. The follow-up was done after 3 months. Results: The sclerotherapy procedure was successful in 40 out of 56 cases $(\mathbf{7 1 . 4 \%})$, and the success rate was $66.7 \%$ in massive effusion and reached $80 \%$ in moderate effusion. Twenty eight patients $(50 \%)$ had to repeat the procedure for a second time, sixteen of which (28.6\%) failed despite the second trial and twelve cases (21.4\%) showed no fluid reaccumulation. Conclusion: Ultrasound-guided iodopovidone sclerotherapy is an effective approach for a successful pleurodesis in hepatic hydrothorax.

Keywords: Pleurodesis; Ultrasound; Iodopovidone;

\footnotetext{
*Disclosure: Nothing to disclose.

No financial support.

Financial conflict: No conflict.

\#Corresponding author.
}

\section{Effusion}

\section{INTRODUCTION}

Hepatic hydrothorax is a complication of end stage liver disease [1], ranging from $4 \%$ to $6 \%$, and up to $10 \%$ with advanced disease [2]. It refers to the abnormal accumulation of more than 500 milliliters of transudative pleural effusion in patients with liver cirrhosis where a cardiac and pulmonary cause of pleural effusion has been ruled out [1].

Mostly this is a right sided effusion, which could be bilateral, and rarely it is isolated left sided effusion. Occasionally, a hepatic hydrothorax may be present in the absence of ascites [3].

Causes of hepatic hydrothorax include leakage from the thoracic duct, leakage through lymphatic channels in the diaphragm and leakage through diaphragmatic defects [4].

The effusion is usually a transudate, however, due to a higher absorptive pleural capacity, the protein content of the pleural effusion is usually slightly higher than that of the ascitic fluid. Transmission of spontaneous bacterial peritonitis to the pleural cavity further changes the criteria of fluid analysis [5]. A chylothorax of cirrhotic origin can rarely be diagnosed by the usual criteria [6]. It was also found that spontaneous empyema can present in $15 \%$ of patients [7].

Traditional treatment of hepatic hydrothorax in a patient who failed medical management of ascites remains problematic and controversial and no guideline for an ideal method is available at the present [8].

Pleurodesis following pleural aspiration decreases the chance of pleural effusion recurrence, and has been a widely used long-standing method of controlling recurrent pleural effusions [9]. 
Placement of a chest tube carries the risk of uncontrollable fluid loss and high mortality [10], however, some pulmonologists are still performing this maneuver and even in their experienced hands there still exists high mortality and difficulty in removal of the chest tube in a considerable number of patients [11].

Videothoracoscopy with subsequent pleurodesis has been proposed as a successful method in the treatment of this condition [12].

The exact mechanism of pleurodesis by a sclerosing agent is not completely understood. However, it has been shown that the initial events that take place after the intrapleural administration of a sclerosing agent include the denudation of mesothelial cells and the subsequent development of an exudative pleural effusion. Thereafter, the complex sequence of events that takes place includes an acute inflammatory response to the local injury, followed by the regeneration of the damaged cells, and the wound strength is established by the migration of connective tissue cells, the synthesis of extracellular matrix proteins and finally collagenisation [13].

Several factors have been reported to influence the outcome of pleurodesis, such as the re-expansion of the collapsed lung, chemical nature of the pleural effusion (PH, glucose, LDH), amount of fluid drained per day and the sclerosing agent used [14].

Subsequently, image-guided percutaneous drainage of accumulated fluid can be beneficial and has been proved to be useful and successful [15].

\section{PATIENTS AND METHODS}

This prospective study included 56 patients with clinical, laboratory and radiological evidence of liver cirrhosis and symptomatic right sided hepatic hydrothorax who were admitted to chest and endemic medicine and hepatology departments, Cairo University Hospital during the period from November 2011 till March 2013.

\subsection{Study Design}

Patients were selected according to the following criteria:

Inclusion criteria included those patients with liver cirrhosis with moderate to massive pleural effusion.

Exclusion criteria included patients with minimal pleural effusion. Hepatic encephalopathy, massive ascites, primary chest disease, malignancy or evidence of portal vein thrombosis.

All patients were subjected to complete history taking, laboratory evaluation including: serum albumin and bilirubin levels, INR, prothrombin time and concentration, $\mathrm{HCV}$ antibody testing, radiological evaluation including abdominal and chest ultrasound and chest X-ray. Patients were classified according to child-pugh score into grade $\mathrm{B}$ and $\mathrm{C}$.
Cases were classified clinically and radiographically according to the amount of pleural fluid into:

1) Massive effusion i.e. pleural fluid reaching above $2^{\text {nd }}$ intercostal space anteriorly.

2) Moderate effusion i.e. pleural fluid between $2^{\text {nd }}$ and $4^{\text {th }}$ intercostals spaces anteriorly.

All patients were kept on close medical management in the form of I.V. albumin, sodium and fluid restriction and proper diuretic therapy.

All patients were subjected to repeated thoracentesis (2 - 5) times according to the size and rate of reaccumulation of the effusion, provided that the maximum amount of drained fluid per session does not exceed 2000 $\mathrm{ml}$. Serial thoracentesis sessions were separated by at least one day in-between. Adequate fluid evacuation and lung re-expansion was radiologically and ultrasono-graphically confirmed.

Under ultrasound guidance, placement of a 16 gauge cannula was done for proper drainage of any detected remnants of pleural fluid collections. Proper evacuation was attempted with a maximum amount of $100 \mathrm{ml}$ allowed to stay in the pleural space. Ten $\mathrm{ml}$ of lidocaine $2 \%$ were injected in the pleural space followed by $20 \mathrm{ml}$ of iodopovidone diluted in $100 \mathrm{ml}$ saline solution. Patients were then asked to change their body position every $15 \mathrm{~min}$ for two hours after the procedure to allow for proper distribution of iodopovidone.

\subsection{Follow Up}

Chest X-rays were performed two hours after the procedure, every other day for one week, and then bi-weekly for three months.

Medical treatment was continued with special regard to salt and fluid restriction, albumin compensation and diuretic therapy during the follow up period.

If any radiological evidence for reaccumulation was noted, another pleurodesis session with the same steps was attempted after one week with continued medical treatment.

The response of pleurodesis was defined based on chest radiograph findings at 3 months follow-up as follows:

1) Successful, i.e. success of treatment was defined by a patient who had no longer dyspnea symptoms and had a chest radiograph that did not show pleural effusion at 1 month after the procedure.

2) Failure, i.e. any fluid re-accumulation after two trial sessions for pleurodesis.

\subsection{Patients Consent}

Informed written consent from each patient and local ethical committee approval were obtained before the study. The study protocol conformed to the ethical guide- 
lines of the 1975 Declaration of Helsinki as reflected in a prior approval by the institution's human research committee.

\subsection{Statistical Analysis}

Data were collected and statistically analyzed using SPSS version 11 statistical package. Comparison of qualitative data was performed with chi square $\left(\mathrm{x}^{2}\right)$ test. The quantitative data were described with mean, standard deviation (SD) or range and compared to ANOVA (analysis of variance). Pearson correlation was conducted to correlate continuous parameters. Spearman correlation coefficient test was used for correlation between nonparametric quantitative data.

\section{RESULTS}

In our study, forty male patients (71.4\%) and sixteen females $(28.6 \%)$ were included with an age range between 44 and 63 years with a mean of 53.5 years. All of our patients had liver cirrhosis secondary to chronic HCV. All of our patients had ascites, lower limb oedema and pleural effusion (Table 1). Child classification is shown in Table 2.

Massive effusion presented in $64.3 \%$ of our patients while moderate effusion presented in $35.7 \%$.

The sclerotherapy procedure was successful in 40 out of 56 cases $(71.4 \%)$, the success rate was $66.7 \%$ in massive effusion and reached $80 \%$ in moderate effusion with no significant difference between the two groups ( $\mathrm{p}$ value $>0.05$ ) (Table 3, Figure 1).

Table 1. Clinical features of the studied patients.

\begin{tabular}{ccc}
\hline & No & $\%$ \\
\hline Jaundice & 13 & $23.2 \%$ \\
Ascites & 56 & $100 \%$ \\
Lower limb oedema & 23 & $50 \%$ \\
Palmar erythema & 31 & $55.3 \%$ \\
Bleeding tendency & 12 & $21.4 \%$ \\
Pleural effusion & 56 & $100 \%$ \\
Total & 56 & $100 \%$ \\
\hline
\end{tabular}

Table 2. Child classification of studied patients.

\begin{tabular}{ccc}
\hline & No & $\%$ \\
\hline Child A & 0 & $0.0 \%$ \\
Child B & 35 & $62.5 \%$ \\
Child C & 21 & $37.5 \%$ \\
\hline
\end{tabular}

Table 3. The relation between the amount of effusion and the outcome of the procedure.

\begin{tabular}{cccc}
\hline & $\begin{array}{c}\text { Massive } \\
\text { effusion } \\
(\mathbf{n = 1 8})\end{array}$ & $\begin{array}{c}\text { Moderate } \\
\text { effusion } \\
(\mathbf{n}=\mathbf{1 0})\end{array}$ & $\begin{array}{c}\text { Total cases } \\
(\mathbf{n}=\mathbf{2 8})\end{array}$ \\
\hline $\begin{array}{c}\text { Repeated } \\
\text { pleurodesis } \\
\text { sessions }\end{array}$ & $\begin{array}{c}20 / 36 \\
(55.5 \%)\end{array}$ & $8 / 20(40 \%)$ & $\begin{array}{c}28 / 56 \\
(50 \%)\end{array}$ \\
Complications & $\mathrm{Nil}$ & $\mathrm{Nil}$ & $\mathrm{Nil}$ \\
Success rate & $24 / 36$ & $16 / 20(80 \%)$ & $40 / 56$ \\
& $(66.7 \%)$ & & $(71.4 \%)$ \\
\hline
\end{tabular}

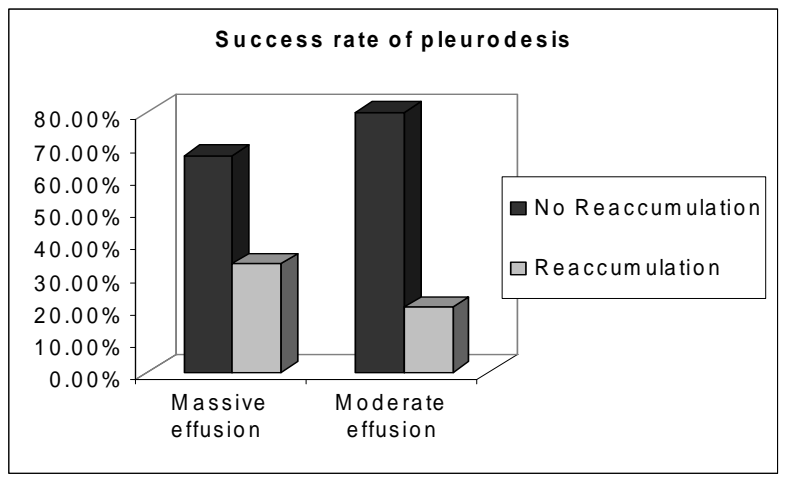

Figure 1. Success rate of pleurodesis.

Twenty eight patients $(50 \%)$ had to repeat the procedure for a second time, sixteen of which (28.6\%) failed despite the second trial and twelve cases $(21.4 \%)$ showed no fluid reaccumulation.

Mean pre-sclerotherapy serum albumin level (one day before pleurodesis) was $3.06 \pm 0.298 \mathrm{~g} / \mathrm{dl}$ in cases with successful pleurodesis with no significant difference ( $p$ value $>0.05$ ) in comparison to cases with failed pleurodesis who had mean pre-sclerotherapy serum albumin level of $2.8 \pm 0.316 \mathrm{~g} / \mathrm{dl}$ (Figure 2).

Out of 40 patients with succeeded pleurodesis $82.5 \%$ has Child B disease and 15\% had child $\mathrm{C}$ disease with high significant difference $\mathrm{p}$ value $<0.001$ (Figure 3).

\section{DISCUSSION}

Numerous studies have evaluated the clinical features, pathogenesis and treatment of hepatic hydrothorax, however, no optimal or standard therapy has been established [16].

Thoracocentesis has been most effective for rapid relief of dyspnea associated with massive hepatic hydrothorax, however, with repeated thoracocentesis in recurrent accumulations there is a risk of substantial protein depletion [8].

A study done by Runyon and co-authors reported two deaths resulting from associated massive protein and electrolyte depletion. They also reported other complications associated with prolonged drainage such as renal 


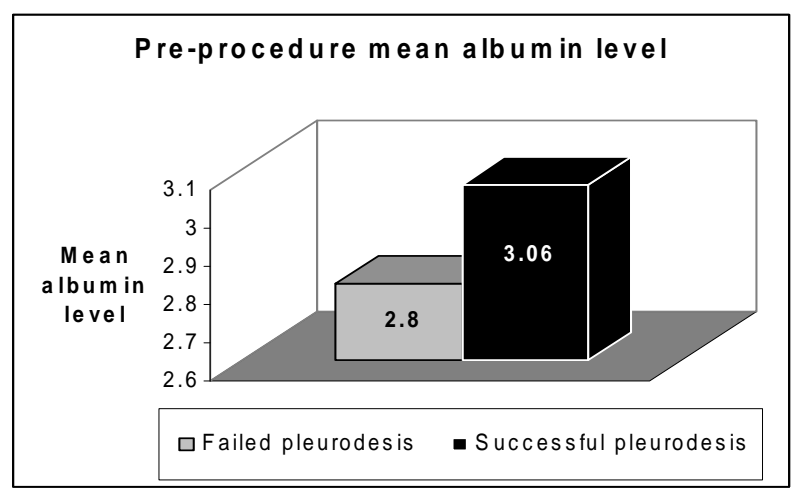

Figure 2. The pre-procedure mean albumin level.

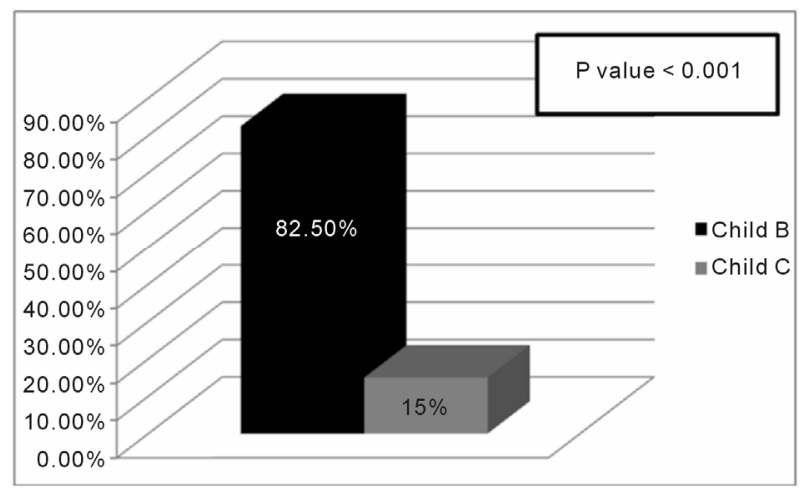

Figure 3. Success rate of pleurodesis in relation to child score.

failure, impaired immunological functions and iatrogenic infection [17].

Prior to the pleurodesis, the pleural fluid should be adequately drained, the compressed lung is in full reexpansion and the daily volume of fluid drainage is below 100 - $150 \mathrm{ml}$ [18].

In this study, Ultrasound guided pleurodesis was attempted for 56 patients. Povidone-iodine (PVP-I) was the sclerosing agent in all cases. Povidone-iodine (PVP-I) is a stable chemical complex of polyvinylpyrrolidone (povidone, PVP) and elemental iodine. It contains $9.0 \%$ available iodine, calculated on a dry basis.

Complete control of the effusion was achieved in 40 cases $(71.4 \%)$. Fluid reaccumulation occurred in 16 patients $(28.6 \%)$, twelve of them presented with mild to moderate encysted pleural effusion below the initial presentation and did not require thoracentesis for respiratory distress. In the other 4 cases, fluid reaccumulation reached the level of initial presentation and required thoracentesis for respiratory distress.

Umit A. et al. observed that the pleurodesis success was significantly decreased if time between the first diagnosis of effusion and onset of chest tube drainage was longer than 30 days; this may be explained by progression of pleural disease or fibrosis of the visceral pleura. Similarly, the success rate was lower if time between chest tube drainage and pleurodesis was longer than 5 days, although not statistically significant [19]. In our study, a success rate of $80 \%$ was achieved in moderate effusions, while a success rate of $66.7 \%$ was observed in massive effusions. The success rate was non-significantly affected by the initial effusion size ( $p$ value $>$ 0.05).

The efficacy of pleurodesis with iodopovidone without any significant adverse effects was $91.6 \%$ in a study conducted by Morales-Gomez et al., [20] and $64.2 \%$ in a study conducted by Kelly-Garcia et al. [21]. This is comparable to our results (success rate $71.4 \%$ ) but in both of these series, pleurodesis was performed through tube thoracostomy.

Talc has been proven to be one of the most effective sclerosing agents for treating malignant pleural effusion [22]. The success rate varies between $88 \%-100 \%$ [23]. Talc poudrage or slurry is usually well tolerated with minimal side effects including pleuritic chest pain and mild fever. However, serious complications have been reported with the use of talc like acute respiratory distress syndrome or acute pneumonitis [24], this might be related to the dose of talc or the physical characteristics (size and type) [25].

In our study, iodopovidone proved to be an extremely effective and safe agent for pleurodesis. No complications were noted in any of our cases with sonographic guided iodopovidone pleurodesis. The efficacy of iodopovidone is comparable to that of talc, but there is no fear of severe complications, such as acute respiratory distress syndrome, which occurs especially if the talc used has a smaller particle size $(<15 \mu \mathrm{m})$. Moreover, pleurodesis with iodopovidone can be performed under local anaesthesia with excellent tolerance and acceptability [26].

Doxycycline can be used as an alternative to tetracycline as they both have similar success rate ranging from $25 \%$ to $100 \%$ [22] and moreover the intravenous form of tetracycline is no longer widely available. However, the main disadvantage associated with doxycycline include the need for repeated instillations to obtain a satisfactory response, patient discomfort and risk of infection resulting from prolonged intercostal tube indwelling time and overall treatment cost [25].

Olivares-Torres and co-authors administered iodopovidone in 52 patients with a success rate of $96 \%$. Intense pleuritic pain and systemic hypertension were encountered after installation of the sclerosing agent, but recovery was the rule [27]. It has been reported that these complications can be related to an inadequate use of analgesia and anesthesia, thus pain control should be individualized [28]. The success rate in our study was comparably less $(71.4 \%)$, yet no intercostal tube insertion was needed, and no complications were at all observed. 
The success rate of pleurodesis was significantly higher in our patients with child B cirrhosis than those with child $\mathrm{C}$. It has been reported that pleurodesis is in generally unsuccessful in child $\mathrm{C}$ cirrhosis because of rapid reaccumulation of fluid that does not allow the visceral and parietal surfaces to adhere; in addition, it is associated with high morbidity and mortality [29].

In conclusion, according to our study, ultrasoundguided iodopovidone sclerotherapy is an effective approach for a successful pleurodesis in hepatic hydrothorax. The procedure offers high success rate (overall rate of 71.4\%), better patient compliance, least complications and precludes the need for intercostal tube insertion and thus offering less discomfort for our patients.

\section{ACKNOWLEDGEMENTS}

To Chest Department and Endemic Medicine and Hepatologhy Department.

\section{REFERENCES}

[1] Strauss, R.M. and Boyer, T.D. (1997) Hepatic hydrothorax. Semin Liver Disease, 17, 227-232. doi:10.1055/s-2007-1007200

[2] Albals, W.M., Salem, A.J., Solomon, D.A., et al. (1991) Hepatic hydrothorax: Cause and management. Archives of Internal Medicine, 151, 2383-2388. doi:10.1001/archinte.1991.00400120029005

[3] Kakizaki, S., Katakai, K. and Yoshinaga, T. (1998) Hepatic hydrothorax in the absence of ascites. Liver, 18, 216220. doi:10.1111/j.1600-0676.1998.tb00154.x

[4] Alberts, W.M., Salem, A.J., Solomon, D.A., et al. (1991) Hepatic hydrothorax. Cause and management. Archives of Internal Medicine, 151, 2383-2388. doi:10.1001/archinte.1991.00400120029005

[5] Ackerman, Z. and Reynolds, T.B. (1997) Evaluation of pleural fluid in patients with cirrhosis. Journal of Clinical Gastroenterology, 25, 619-622. doi:10.1097/00004836-199712000-00014

[6] Romero, S., Martín, C., Hernandez, L., et al. (1998) Chylothorax in cirrhosis of the liver-Analysis of its frequency and clinical characteristics. Chest, 114, 154-159. doi:10.1378/chest.114.1.154

[7] Xiol, X., Castellote, J., Cortes-Beut, R., et al. (2001) Usefulness and complications of thoracocentesis in cirrhotic patients. American Journal of Medicine, 111, 67-69. doi:10.1016/S0002-9343(01)00744-6

[8] Milanez de Campos, J.R., Filho, E.A., Webre, E.C., et al. (2000) Thoracoscopy and talc poudrage in the management of hepatic hydrothorax. Chest, 118, 13-17. doi:10.1378/chest.118.1.13

[9] Zaloznik, A.J., Oswald, S.G. and Langin, M. (1983) Intrapleural tetracycline in malignant pleural effusions. Cancer, 51, 752-755. doi:10.1002/1097-0142(19830215)51:4<752::AID-CNC $\underline{\mathrm{R} 2820510434>3.0 . \mathrm{CO} ; 2-7}$
[10] Borchardt, J., Smirnov, A., Metchnik, L., et al. (2003) Treating hepatic hydrothorax. British Medical Journal, 326, 751-752. doi:10.1136/bmj.326.7392.751

[11] Liu, L., Haddadin, H.A., Bodian, C.A., et al. (2004) Outcome analysis of cirrhotic patients undergoing chest tube placement. Chest, 126, 142-148. doi:10.1378/chest.126.1.142

[12] Ferrante, D., Arguedas, M.R., Cerfolio, R.J., et al. (2002) Video-assisted thoracoscopic surgery with talc pleurodesis in the management of symptomatic hepatic hydrothorax. American Journal of Gastroenterology, 97, 31723175. doi:10.1111/j.1572-0241.2002.07126.x

[13] Kotran, R., Kumar, V. and Collins, T. (1999) Robbins pathologic basis of disease. 6th Edition, WB Saunders, Philadelphia, 89-134.

[14] Walker-Renard, P.B., Vaughan, L.M. and Sahn, S.A. (1994) Chemical pleurodesis for malignant pleural effusions. Annals of Internal Medicine, 120, 56-64. doi:10.7326/0003-4819-120-1-199401010-00010

[15] Merriam, M.A., Cronan, J.J., Dorfman, G.S., et al. (1988) Radiographically guided percutaneous catheter drainage of pleural fluid collections. American Journal of Roentgenology, 151, 1113-1116. doi:10.2214/ajr.151.6.1113

[16] Cardenas, A., Kelleher, T. and Chopra, S. (2004) Review article: Hepatic hydrothorax. Aliment Pharmacological Therapy, 20, 271-279. doi:10.1111/j.1365-2036.2004.02081.x

[17] Runyon, B.A., Greenblatt, M. and Ring, M.H.C. (1986) Hepatic hydrothorax is a relative contraindication to chest tube insertion. American Journal of Gastroenterology, 81, 566-567.

[18] Ruckdeschel, J.C., Moores, D., Lee, J.Y., et al. (1991) Intrapleural therapy for malignant pleural effusions: A randomized comparison of bleomycin and tetracycline. Chest, 100, 1528-1535. doi:10.1378/chest.100.6.1528

[19] Umit, A., Servet, O., Levent, C., et al. (2009) Bedside talc pleurodesis for malignant pleural effusion: Factors affecting success. Annals of Surgical Oncology, 16, 745750. doi:10.1245/s10434-008-0263-x

[20] Morales-Gomez, J., Tellez-Becerra, J.L., Martinez-Ormeno, J.E., et al. (1993) Pleurodesis with iodopovidone in malignant pleural effusions. Revistadel Instituto Nacionalde Enfermedades Respiratorias Mexico, 6, 71-74.

[21] Kelly-Garcia, J., Roman-Berumen, J.F. and Ibarra-Perez, C. (1997) Iodopovidone and bleomycin pleurodesis for effusions due to malignant epithelial neoplasms. Archives of Medical Research, 28, 583-585.

[22] Barbetakis, N., et al. (2004) Mitoxantrone pleurodesis to palliate malignant pleural effusion secondary to ovarian cancer. BMC Palliative Care, 3, 4. doi:10.1186/1472-684X-3-4

[23] Shaw, P. and Agawal, R. (2004) Pleurodesis for malignnant pleural effusion. (Cochrane Review) The Cochrane Library, 4.

[24] Steven, A.S. (2001) Malignant pleural effusion. Seminars in Respiratory and Critical Care Medicine, 22, 607-615. doi:10.1055/s-2001-18796

[25] Antunes, G., et al. (2003) BTS guidelines for the mana- 
gement of malignant pleural effusions. Thorax, 58, 11291138. doi:10.1136/thorax.58.suppl 2.ii29

[26] Maskell, N.A., Lee, Y.C., Gleeson, F.V., et al. (2004) Randomized trials describing lung inflammation after pleurodesis with talc of varying particle size. American Journal of Respiratory and Critical Care Medicine, 170, 377-382. doi:10.1164/rccm.200311-15790C

[27] Olivares-Torres, C.A., Eaniado-Eaborin, R., Chavez-Garcia, C., et al. (2002) Lodopovidone pleurodesis for recurrent pleural effusions. Chest, 122, 581-583. doi:10.1378/chest.122.2.581

[28] Brant, A. and Eaton, T. (2001) Serious complications with talc slurry pleurodesis. Respirology, 6, 181-185. doi:10.1046/j.1440-1843.2001.00327.x

[29] Gines, P., Arroyo, V., Rodes, J. and Schrier, R. (2005) Ascites and renal dysfunction in liver disease: Pathogenesis diagnosis and treatment. 2nd Edition, Blackwell Publishing Ltd. doi:10.1002/9780470987476 